\title{
FABRICATION OF PCL-COLLAGEN NANOFIBER USING CHLOROFORM-FORMIC ACID SOLUTION AND ITS APPLICATION AS WOUND DRESSING CANDIDATE
}

\author{
Tri Prasetyo Armedya ${ }^{1}$, Muhammad Fathan Dzikri ${ }^{1}$, Mochamad Zakki Fahmi ${ }^{1}$, Yanuardi \\ Raharjo $^{1}$, Siti Wafiroh ${ }^{1}$, Purwati $^{2}$
}

${ }^{1}$ Department of Chemistry, Faculty of Science and Technology, Airlangga University ${ }^{2}$ Stem Cell Research and Development Center, Universitas Airlangga Surabaya, East Java, Indonesia.

\begin{abstract}
In this study, polycaprolactone-collagen nanofiber was prepared with $10 \% \mathrm{w} / \mathrm{v}$ composition using a mixture of chloroform-formic acid. PCL was dissolved in chloroform while collagen was dissolved in formic acid. This research carried out optimization of electrospinning parameters such as flow rate, running time, and collector type to obtain optimum and suitable nanofiber to be applied as wound dressing. The most optimum nanofiber is made with flow rate $0.01 \mu \mathrm{L} / \mathrm{h}$, running time is 3 hours, and using cylinder collector type. Characterization was performed for five different types of PCL-collagen nanofiber with different treatment, which nanofiber made with cylinder collector, plate collector, addition ofcitric acid, heating treatment, and nanofiber without the addition of collagen. PCL-collagen nanofiber produces smaller diameter about $200-600 \mathrm{~nm}$. Based on the test of mechanical properties, addition of collagen causes its mechanical properties to be lower when compared to addition of crosslinking agents by heating or citric acid. The cytotoxicity test was carried out for PCL, PCLcollagen withaddition of citric acid, and PCL-collagen nanofiber treated by heating. PCL was chosen to compare the effect of collagen addition onnanofiber against cell viability. Collagen has an important role for growth, proliferation, and differentiation of cells in tissue engineering. PCLcollagen nanofiber which treated by heating provides better viability of $83.09 \%$ while compared to nanofiber with addition of citric acid, because citric acid acidic properties causing the environment around nanofiber have an extreme $\mathrm{pH}$, it may affect the growth of cells and reduce its viability.
\end{abstract}

\section{Keywords:Nanofiber, PCL, collagen, electrospinning, wound dressing, MTT Assay}

\section{INTRODUCTION}

Development of technology support researchers to develop fabrication of wound dressing materials which can be applied for wound healing process. Over the last decade, nanofiber membranes have interested many researchers because of its extensive application for medical field, particularly as wound dressing. The techniques used in fabrication of nanofiber include drawing, template synthesis, phase separation, selfassembly, and electrospinning techniques (Huang et al., 2003). Among these techniques, electrospinning is techniques that most widely studied and used by researchers today, because it provides good nanofiber results to be applied 
in tissue engineering, especially as wound dressings.

Synthetic polymeric materials often used for fabrication of nanofiber, but it most have poor biocompatible properties, thus to overcome these constraints used natural polymers which have good biocompatible properties (Huang et al., 2003). Collagen isnatural polymer that most widely used in medical applications because its properties resembles human extracellular matrix.Meanwhile, polycaprolactone is synthetic polymer which has an aliphatic polyester group, good mechanical properties, and non-toxic for human skin (Dulnik et al., 2016). Polycaprolactone (PCL) has strong hydrophobic properties, but it can be reduced by the addition of hydrophilic substances such as gelatin or collagen.

Recent studies reported that nanofiber was made of collagen and polycaprolactone provide good materials combination to be applied as wound dressings. The advantages of these two materials are their skin-like properties and human extracellular matrix (Zhang et al., 2005). In this study also aim to developed suitable solvent system and determine the optimum parameters for electrospinning PCL-collagen nanofiber. These researches areusing binary solvent system which chloroform for PCL and formic acid for collagen.Generally, the usage of chloroform as a PCL solvent has been widely performed in fabrication of nanofiber which produces diameter of about $3-5 \mu \mathrm{m}$. Based on Schueren et al reported the development of new solvent system for PCL, which is solvent mixture of chloroform and formic acid can produce nanofiber with diameter about ten times smaller than chloroform only as a PCL solvent. In addition, formic acid may also used as a solvent for collagen besides acetic acid (Schueren et al., 2011).

The application of PCL-collagen nanofiber as wound dressing was performed by in vitro cytotoxicity test using MTT Assay.The results of the test were demonstrated by the number viability of living cells cultured on nanofiber.Therefore, it may hope that fabrication of PCL-collagen nanofiber using chloroform-formic acid can be a solution to produces wound dressings which have biocompatible, biodegradable, and non-toxic properties for human skin.

\section{MATERIALS AND METHODS}

\subsection{Materials}

PCL $(\mathrm{Mw}=80.000)$ was purchased from Sigma-Aldrich, while collagen was obtained from BATAN Jakarta. Analytical grade formic acid were purchased from Merck Co. Huh7 cells, NaOH, Dulbeco's Modified Eagle Medium (DMEM) cell culture medium, Fetal Bovine Serum (FBS), Phosphate Buffered Saline (PBS), MTT (3-(4,5-dimethyltiazole-2yl)-2,5-diphenyltetrazrazine bromide), dimethyl sulfoxide (DMSO) were obtained from Institute of Tropical Disease Airlangga University. 


\subsection{Methods}

\subsubsection{Preparation of PCL-collagen polymer solution}

In this study, preparation of polymer solutions for nanofiber is by dissolving PCL and collagen separately. PCL was dissolved in chloroform meanwhile collagen was dissolved in formic acid. Both solutions are stirred with magnetic stirrer until homogeneous. After stirring, both of solutions mixed and stirred untilthe mixtures form homogeneous solution. The polymer solution mixture allowed for a while to remove gas bubbles that arise duringthe mixing process.

\subsubsection{The electrospinning process of PCL-} collagen nanofiber

Electrospinning process are using high voltage power supply which set of $15 \mathrm{kV}$. Collector was installed at $10 \mathrm{~cm}$ distance from the tip of syringe. The clamping cable from power supply was clipped to syringe and the other one was connected to collector. Furthermore, PCL-collagen polymer solution injected into syringe and the electrospinning process was carried out with flow rate, running time, and type of collector to be optimized. This optimization aims to get the optimum nanofiber to be applied as wound dressing.

\subsubsection{Optimization of electrospinning parameters}

In this research, some electrospinning parameters to be optimized which are flow rate, running time, and collector type to obtain optimum and suitable nanofiber to be applied as wound dressing. Variations of flow rate used were $0.01,0.05,0.1$, and $0.5 \mu \mathrm{L} / \mathrm{h}$ to obtain optimum dop flow rate in fabrication of nanofiber. Meanwhile the optimization of running time was done with variations of time $1,3,5$, and 7 hours. The result of flow rate and running time optimization will be used as reference on optimization of collector type. The collectors used in this research are cylindrical and flat collectors.

\subsubsection{Characterization of PCL-collagen nanofibers}

At this stage, the characterization performed for five different types of PCLCollagen nanofiber with different treatment variations. The treatments include PCLCollagen nanofiber made with cylindrical and flat collectors, addition of citric acid, heating treatment, and without the addition of collagen.These five nanofiber membranes was made based on electrospinning parameters which have been optimized.

\subsubsection{Scanning Electron Microscope morphological analysis}

Determination of PCL-Collagen nanofibers morphology were performed using Scanning Electron Microscope (SEM). The cross section or surface of nanofiber sample will be enlarged at certain magnification by SEM analysis. The morphological test with SEM was performed to find out the surface structure and diameter of PCL-Collagen nanofiber. 


\subsubsection{Mechanical properties analysis}

The mechanical properties of nanofibers were analyzed by tensile tests using Autograph. This mechanical properties test was performed to determine mechanical strength ofPCL-Collagen nanofiber against the force given from the outside. This tensile test data was used for determining stress, strain, and nanofiber membrane module.

\subsubsection{Cytotoxicity properties analysis}

Prior to in vitro assay with Huh7 cells, PCL-collagen nanofiber was sterilized with UV light for 48 hours.To evaluate cell metabolism in PCL-collagen nanofiber, MTT test for nanofiber membrane was made after 48 hours, the amount of cells that had been seeded is $5.4 \times 10^{4}$ cells/membranes density. MTT test depends on cellular reduction of MTT which have yellow color, by mitochondrial dehydrogenase enzyme from living cells forming blue to purple formazan crystals. The amount of formazan crystals formed comparable with the amount of living cells. The culture medium in well was removed and the incubated PCL-Collagen nanofiber sample was added $300 \mu \mathrm{L}$ medium containing MTT solution with 9:1 (DMEM $270 \mu \mathrm{L}+$ MTT $30 \mu \mathrm{L}$ ) ratio, then incubated for $4 \mathrm{~h}$ at $37^{\circ} \mathrm{C}$ and $5 \% \mathrm{CO}_{2}$. After 4 hours, the culture medium was taken from container and
$200 \mu \mathrm{L}$ of dimethyl sulphoxide (DMSO) was added to dissolve the precipitate formazan crystals formed from the reaction of MTT [5]. Measurement of formazan crystals absorbance was done at $560 \mathrm{~nm}$ and $750 \mathrm{~nm}$ wavelength with GloMax-Multi Microplate Multimode Reader (Promega).

The absorbance data obtained was used to determine the percentage of living cells (cell viability). If the percentageless than $60 \%$, it is mean toxic and can kill living cells. Measurement results were compared with controls. MTT Assay controlsare Huh7 cells which had been seeded in culture medium at well without the addition of nanofiber sample.

\section{RESULTS AND DISCUSSION}

\subsection{Preparation of PCL-collagen polymer solution}

Polymer solution for nanofiber membrane was prepared by dissolving PCL and collagen separately. The total composition of PCL and collagen made is $10 \% \mathrm{w} / \mathrm{v}$. PCL was dissolvedin chloroform meanwhile collagenwas dissolved in formic acid. Both solutions are stirred until homogeneous. Furthermore, both of solutions were mixed together and stirred until form homogeneous solution. Then polymer solution mixture was allowed for a while to remove gas bubbles that arise during the mixing process. 


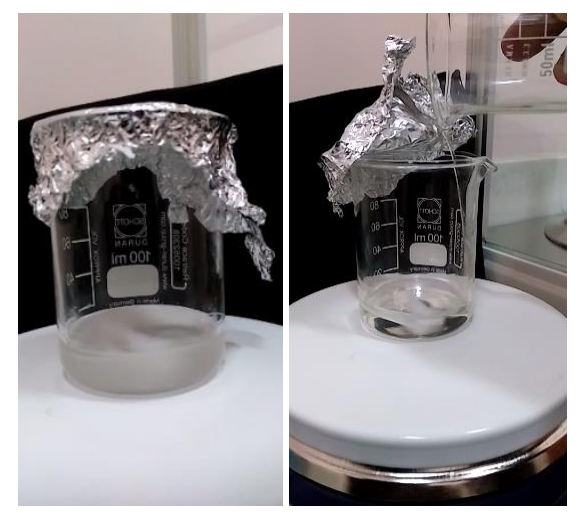

Figure 1. Preparation of PCL-collagen solution

\subsection{Electrospinning process of PCL-}

\section{collagen nanofiber}

The electrospinningprocesses are using high voltage power supply which has been set of $15 \mathrm{kV}$. The collector installed at $10 \mathrm{~cm}$ distance from the tip of syringe. The principle of electrospinning is polymer solution in a syringe whichhas given high electric potential with a range of several kilovolts, it will affect the surface tension of polymer solution forming conical shaped extension called Taylor Cone at the tip of syringe, and then polymer jet was attracted to the collector forming the continuous fibers. The formed fibers will become thinner due to evaporation of the solvent (Buttafoco et al., 2006).

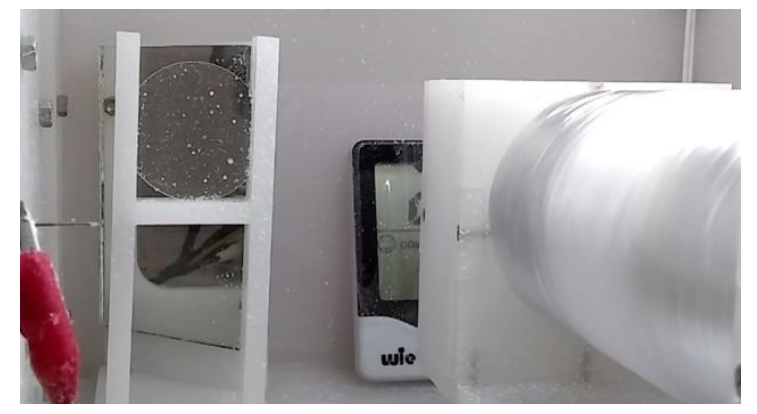

Figure 2.Electrospinning process of PCL-Collagen nanofiber

\subsection{Optimization of electrospinning}

\section{parameters}

\subsubsection{Optimization of flow rate}

Based on this optimization result obtained the most optimum flow rate was $0.01 \mu \mathrm{L} / \mathrm{h}$. Taylor Cone which produced at this flow rate has perfectly conical shape, the polymer solution stream is not very fast, and not discard the dop, and produces continuous fibers. At flow rate above $0.01 \mu \mathrm{L} / \mathrm{h}$, more elongated Taylor Cone, not continuous fibers formed, and polymer solutions coming out of the syringe still wet as the flow accelerate with increasing of flow rate, forming hole-shaped at 
nanofibers. In the research of Maneji et al states that the increasing flow rate of polymer solution in the electrospinning process produces larger diameter of nanofibers (Maneji et al., 2014).

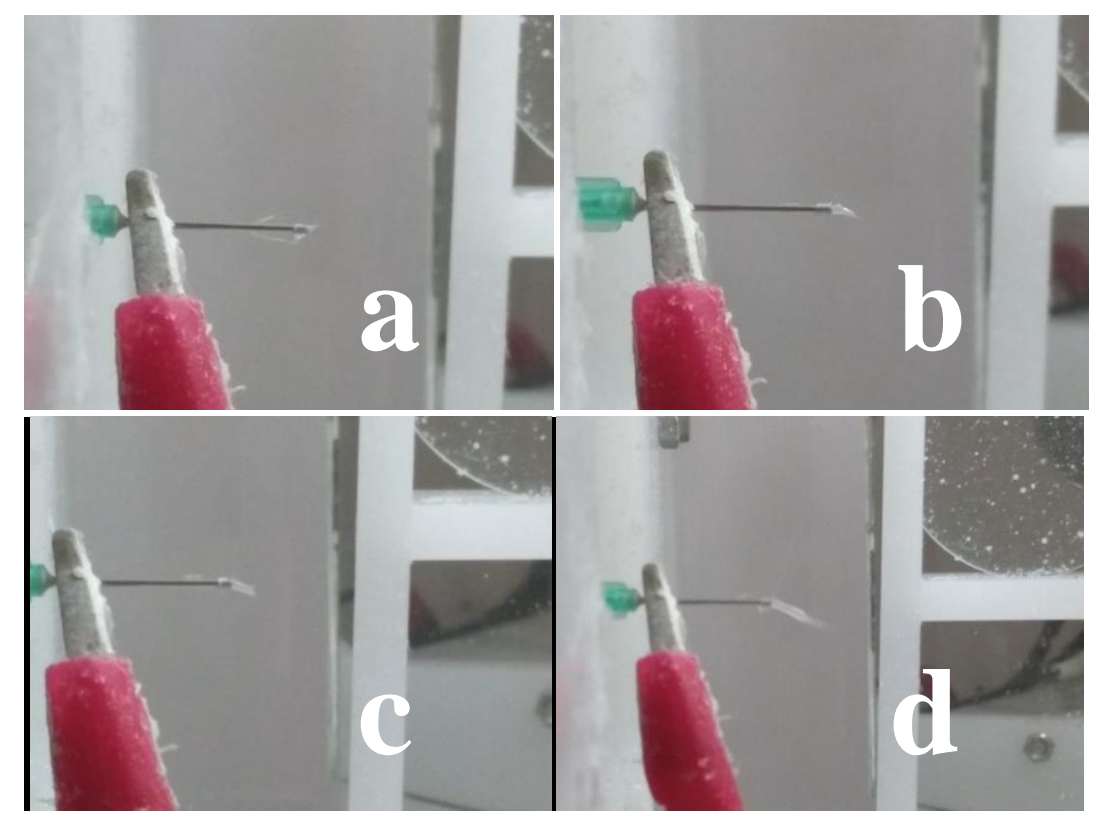

Figure 3. Taylor Cone formation (a) $0.01 \mu \mathrm{L} / \mathrm{h}$, (b) $0.05 \mu \mathrm{L} / \mathrm{h}$, (c) $0.1 \mu \mathrm{L} / \mathrm{h}$, (d) $0.5 \mu \mathrm{L} / \mathrm{h}$

Flow rate in the electrospinning process not always produce continuous fibers, this may occur due to occasional deformation as a result of competition between polymer flow rate coming out of syringe slower to be drawn by electrostatic field generated to the collector.With increasing of flow rate, nanofibers were formed from polymer solution not get enough time to dry before reaching the collector, so it form a large diameter nanofiber (Rajput, 2012).

\subsubsection{Optimization of running time}

Based on the experimental results, more time of electrospinning process produce thicker nanofibers. This nanofiber thickness affects the cells to be applied to nanofiber, the nanofibers surface is useful as cells sticking medium andgrowth. As the nanofiber thickness grows, it is feared that cells can not stick and grow well.Based on this optimization result, running time of electrospinning process for 3 hours was choosen because it is resulting nanofiber which not very thin and thick, and it can be separated from aluminum foil of collector, so it was expected to be used as cell medium to stick and grow. The resulting membrane with electrospinning time duration of 5 and 7 hours were very thick and it easily separated. While the membrane produced with 1 hour electrospinning duration was thinner and difficult to separate from aluminum foil. 


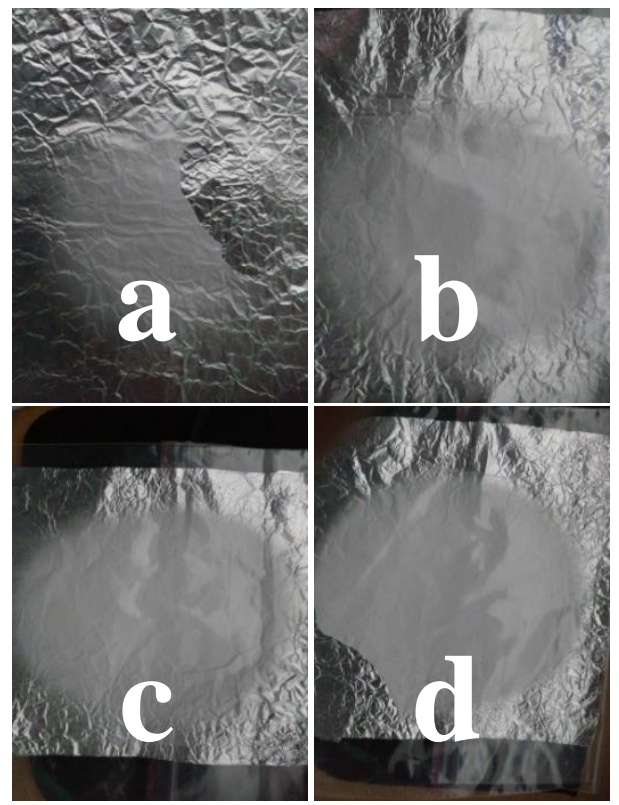

Figure 4. Optimization of running time (a) 1 h, (b) $3 \mathrm{~h}$, (c) $5 \mathrm{~h}$, (d) $7 \mathrm{~h}$

\subsubsection{Optimization of collector type}

This optimization process was done by using flow rate and running time which has been optimized previously, which $0.01 \mu \mathrm{L} / \mathrm{h}$ of flow rate and duration of running time for 3 hours.Optimization using flat collector produces uneven and thicker membranes in the center of nanofiber. This may because during the electrospinning process, the syringe which containing polymer solution was centered only towards the center of flat collector, so it formed nanofiber distribution in the center only and thicker.While optimization using cylindrical collector produceswas more evenly distributed nanofiber membrane and thickness. This may influenced by the nature of its rotating collector, so it formed more evenly distributed nanofiber to all parts of the collector. The cylindrical collector has properties to expand the nanofiber formed due to its influence of rotation (Pra et al., 2017).

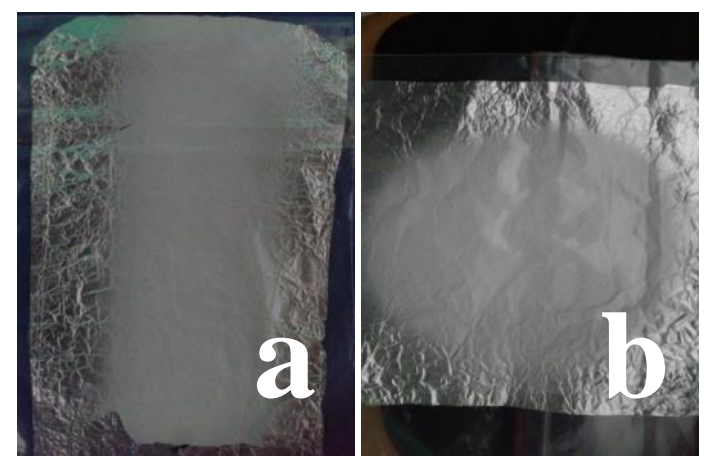

Figure 5. Optimization of collector type (a) cylindrical, (b) flat 


\subsection{Characterization of PCL-collagen nanofiber}

The treatment of nanofiber aims to compare the effectiveness of most optimal PCLcollagen nanofiber used as wound dressing. Five nanofiber was made based on electrospinning parameters which have been optimized previously using $0.01 \mu \mathrm{L} / \mathrm{h}$ of flow rate, running time for 3 hours, and cylindrical collector usage, except for PCL-collagen nanofiber made by flat collector.PCL-collagen nanofibers were made by flat collector used as comparison for nanofiber which made by cylindrical collector. The addition of citric acid and heating treatment in oven $45^{\circ} \mathrm{C}$ for 2 hours, serves as crosslinking method to strengthen structure and improve mechanical properties of nanofibers. While the nanofiber which not added by collagen used as comparison to investigate the effectiveness of membranes with or without addition of collagen.

\subsubsection{Scanning Electron Microscope morphological analysis}

Scanning Electron Microscope analysis was performed to determine surface morphological and diameter of PCL-collagen nanofiber. The ideal criteria of nanofiber to be applied as wound healing was $50-500 \mathrm{~nm}$ of diameter because its size resemble physical structure of human extracellular matrix. In addition, large surface areas support homeostasis during the healing process (Abrigo et al., 2014
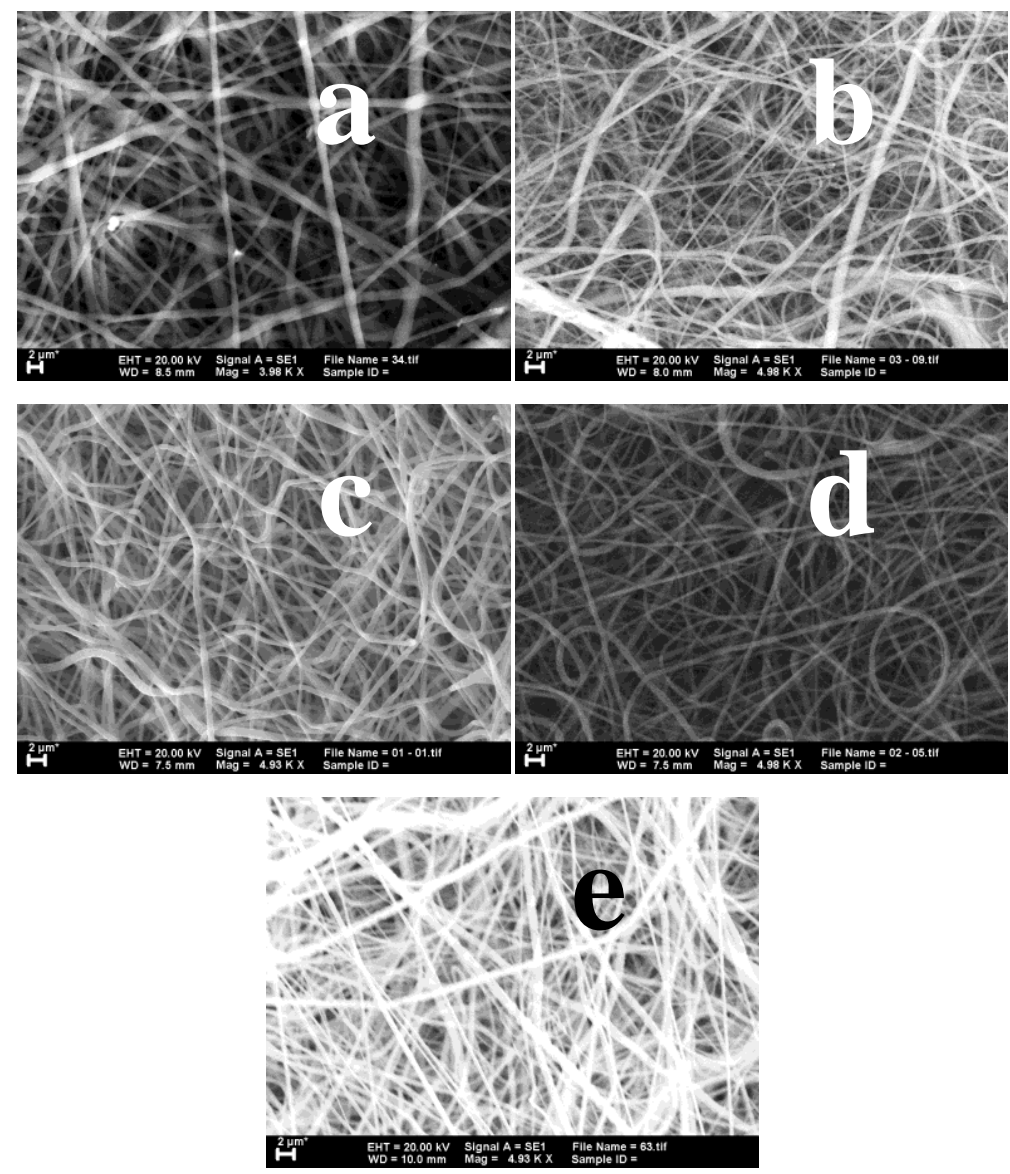
Figure 6. SEM image results of PCL-collagen nanofibers with variation of treatments (a) cylindrical collector, (b) flat collector, (c) addition of citric acid, (d) heating-treated, (e) without addition of collagen

Based on the SEM image, nanofiber was made from PCL-collagen (Figure 6a-6d) has diameter of about 200-600 nm, while nanofiber which made from PCL only (Figure 6e) has $800-2000 \mathrm{~nm}$ of diameter. This suggests that the usage of chloroform-formic acid solvents has an influence on nanofiber morphology. In accordance with research of
Schueren et alwhichdeveloped new solvent system in the fabrication of PCL nanofiber, in which a solvent mixture of chloroform and formic acid produces nanofiber with diameter of ten times smaller than chloroform only as PCL solvent (Schueren et al., 2011). On the other hand, formic acid may also be used as solvent for collagen besides acetic acid.

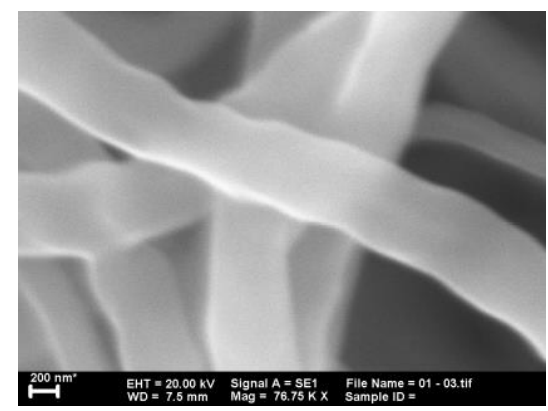

Figure 7. Cross section parts

Figure $6 c$ was the SEM image of PCLcollagen nanofiber with addition of citric acid. Citric acid serves as crosslinking agent to strengthen membrane structure which formed. Figure $6 \mathrm{c}$ shows that nanofiber structure has more cross-linked parts.The formation of cross section occurs because of the chemical bond between citric acid, PCL, and collagen. At cross section parts has a level of more $\mathrm{O}$ than $\mathrm{C}$ atoms, so the chemical bonds formed was made nanofiber becomes more strength. It supported by SEM EDX data which describes the atomic content of a sample. Based on SEM EDX data shows that $\mathrm{C}$ and $\mathrm{O}$ atoms content in the cross section parts (Figure $8 b$ ) has a ratio of $3.61(78.12 / 21.63)$,meanwhile the noncross section parts (Figure 8a) has a ratio of 5.92 (85.22/14.39). From these data, the smaller ratio value indicates the presence of more $\mathrm{O}$ atoms. Citric acid (C6H8O7) was crosslinking agents which have seven $\mathrm{O}$ atoms allowing more chemical bonds to be formed. 

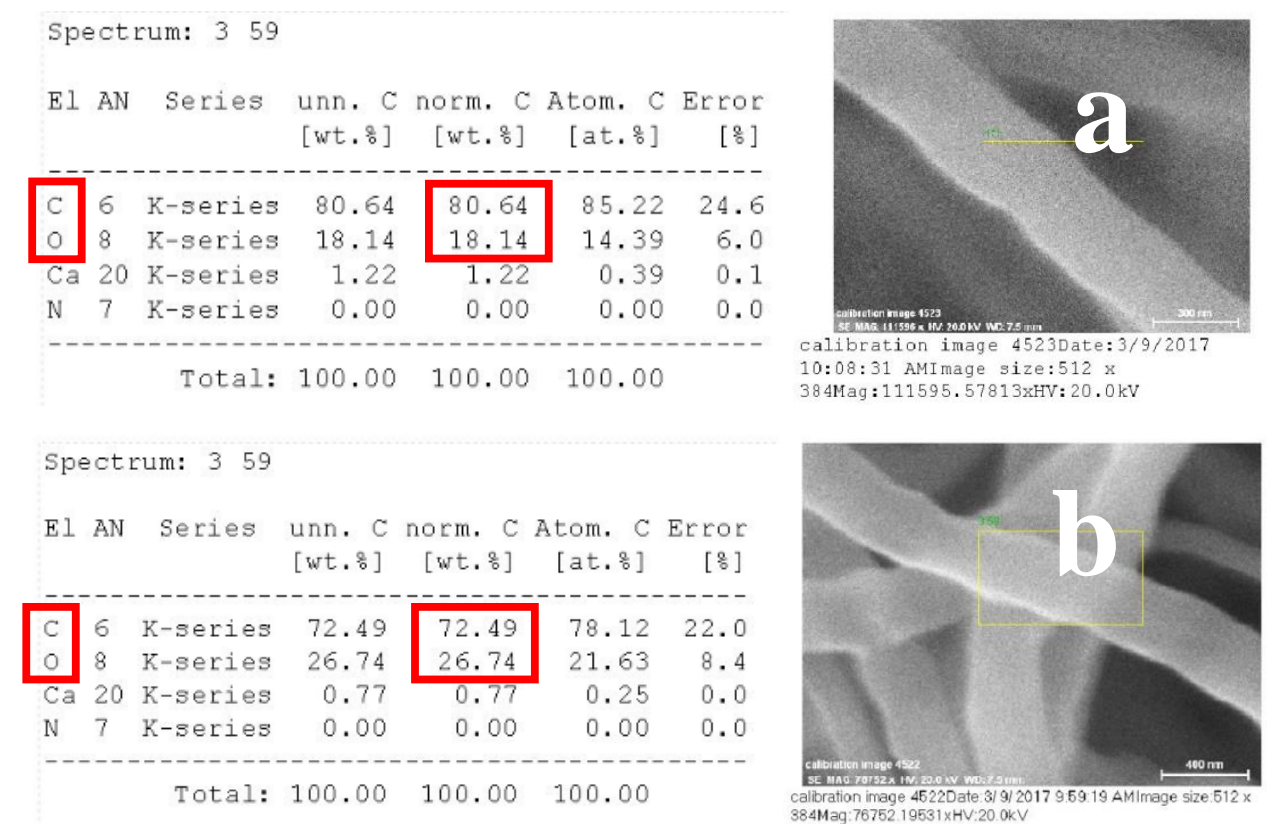

Figure 8. SEM EDX results (a) non cross section parts, (b) cross section parts

Figure 6d was SEM image of PCL-collagen nanofiber treated by heating in a $45^{\circ} \mathrm{C}$ oven for 2 hours. Based on these images, nanofiber structure has morphology which is no different with the nanofiberbeen made by cylindrical collector. On the other hand, the presence of heating was feared to damage collagen content because it was a polymer composed of proteins. Collagen hasdenaturation temperature of $45^{\circ} \mathrm{C}$ (Nomura et al., 1996). Protein was macromolecule which not resistant to high temperatures, so that its structure becomes denatured. According this damage can reduce the effectiveness of nanofiber in wound healing because nanofiber used as a cell medium to stick and grow.

On Fig,6e was morphology of PCL nanofiber without the addition of collagen. From these SEM image result shows morphological structure not much different to
PCL-collagen nanofiber (Figure 6a), as well as the heat-treated nanofiber (Figure 6d). However, this nanofiber structure has larger diameter when compared to collagen-treated nanofiber. Nanofiber was made of PCL (Figure 6e) has diameter of about 800-2000 nm.

\subsubsection{Mechanical properties analysis}

The mechanical properties of nanofiber were performed by tensile test using Autograph. This mechanical properties test performed to determine the strength of the PCL-collagen nanofiber membrane against the force given from outside. The tensile test data used to determine stress, strain, and nanofibers moduli. According the experimental results, different treatment giving different stress, strain, and modulus young values. 


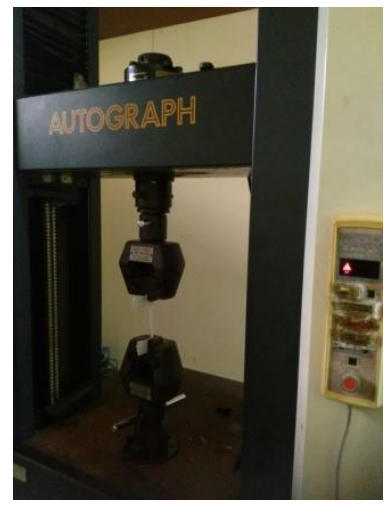

Figure 9. Mechanical properties test using Autograph

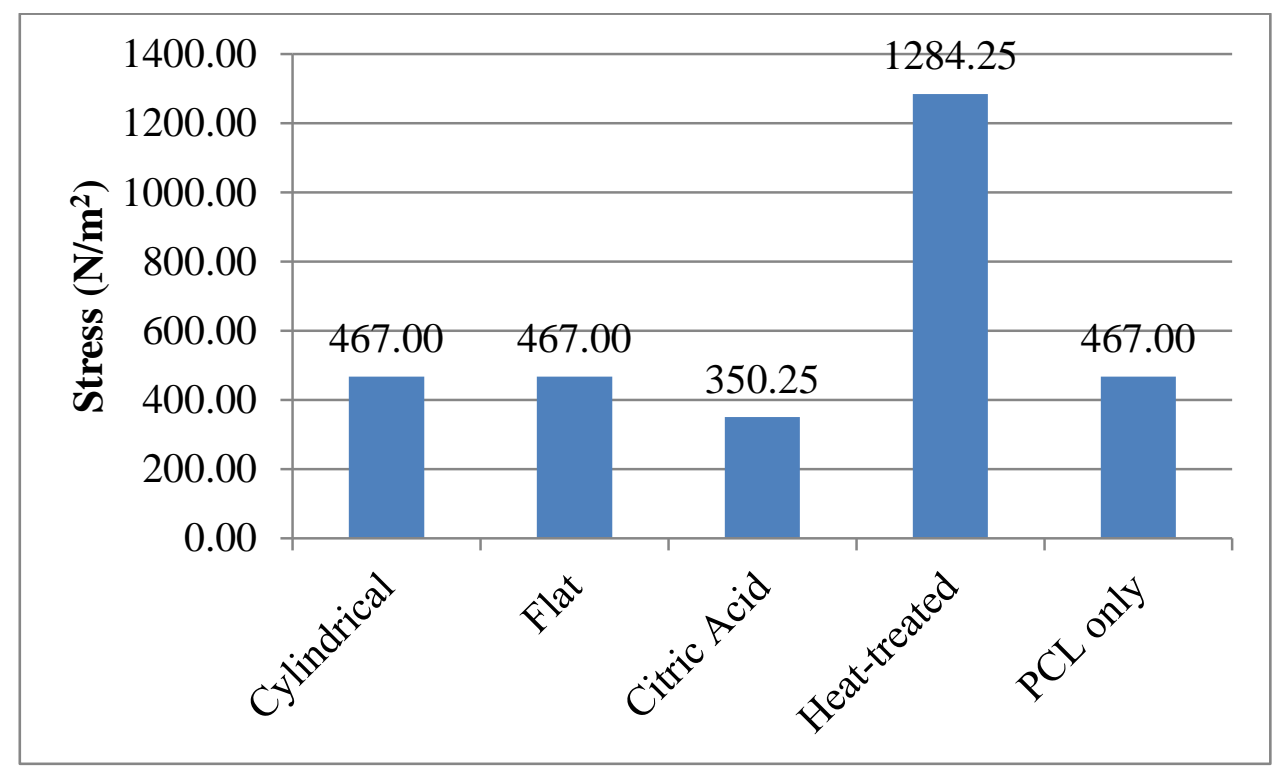

Figure 10. Measurement results of nanofiber stress

Based on the graph in Fig.10, showed that PCL-collagen nanofiber was made by cylindrical and flat collectors and PCL only without addition of collagen has the same stress value of $467 \mathrm{~N} / \mathrm{m}^{2}$. While the heattreated PCL-collagen nanofiber was has the greatest stress value of $1284.25 \mathrm{~N} / \mathrm{m}^{2}$. Contrast to PCL-collagen nanofiber with the additionof citric acid has the lowest stress value of 350.25 $\mathrm{N} / \mathrm{m}^{2}$. The process of heating and addition of citric acid serves to improve the mechanical properties of nanofibers. Citric acid formed crosslinking parts through chemical bonds between atoms. Heating was physical crosslinking method which will break the bonds in the membrane (Amalia, 2012). Materials which havemore chemical bonds will have more strength mechanical properties, so it tends to have greater value of young modulus. The increasingly of young modulus values has a higher stress but smaller strain value (Callister and Rethwisch, 2014). However, based on experimental results, nanofiber with the addition of citric acid did not show these properties. 


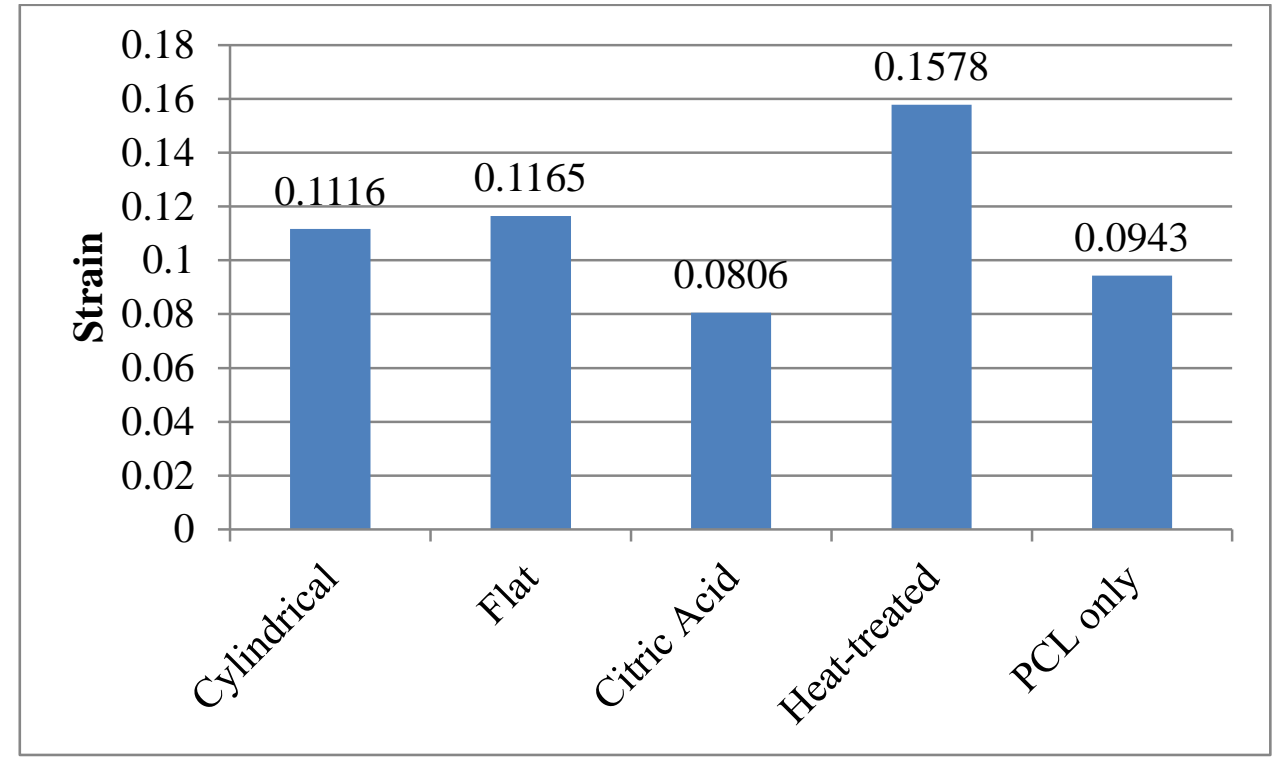

Figure 11. Measurement results of nanofiber strain

Strain value used to determine the elastic properties of a material, which has the ability of an objectto return to its original state after being subjected byan external force. PCLcollagen nanofiber heat-treatedhas a larger strain of 0.1578 . This may effects of heat dissipation of chemical bonds between atoms in the nanofiber thus increasing membrane strain with the increasing length of nanofiber
(Amalia, 2012). While nanofiber with the addition of citric acid gives lowest strain value of 0.0806 because crosslinker agent caused the bond in membrane becomes strongly bound to produce a small strain. Both PCL-collagen nanofiber was made by cylindrical and flat collectors has similar strain values whereas PCL nanofiber without the addition of collagen has a lower strain.

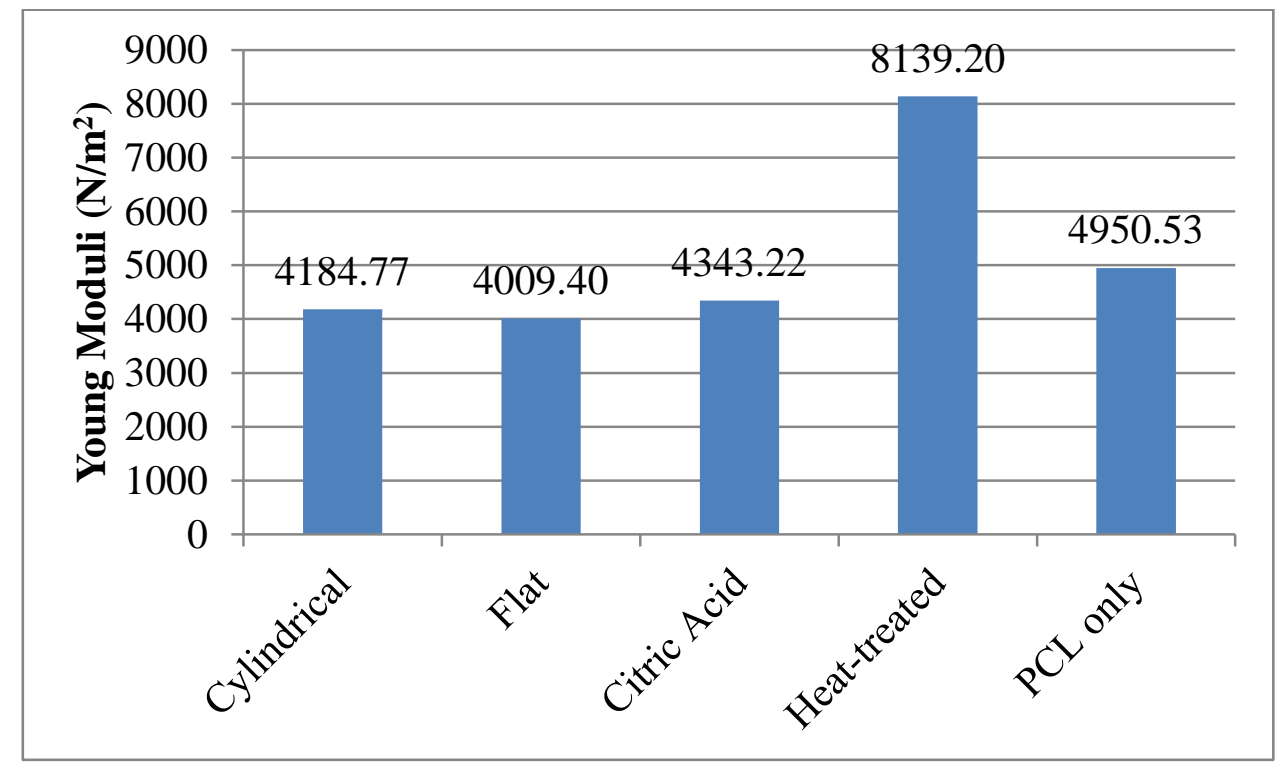

Figure 12. Measurement results of nanofiber young modulus 
Young modulus value obtained from the comparison of stress to strain values. PCL was abiodegradable synthetic polymer which has good mechanical properties and non-toxic for human skin (Dulnik et al., 2016). PCL can be combined with other polymers to improve polymer stress resistance. Based on the results, the PCL nanofiber without the addition of collagen has a higher young modulus value thanPCL-collagen nanofiber, so the addition of collagen mayeffect of decreasing the mechanical properties of membrane and not all polymers have effective to improve mechanical properties of membrane. While, nanofiber which was giving heat-treatment and addition of citric acid as a crosslinking agent has higher young modulus value. Heating and addition of crosslinker agents were method to improve the mechanical properties of a material. Heating was physical crosslinking while citric acid was chemical crosslinking (Amalia, 2012).

\subsubsection{Cytotoxicity properties analysis}

Prior to in vitro assay with Huh7 cells the PCL-collagen nanofiber membrane was sterilized with UV light. This sterilization process serves as a disinfectant to kill bacteria or microbes that can interfere within cell cultured in nanofibers (Zeybek et al., 2014).

The nanofiber cytotoxicity test was performed with MTT Assay to determine percentage of cell viability. The cells used in this cytotoxicity test were Huh7 cells originating from the liver. Viability is the cell's ability to survive in samples to be tested. MTT Assay depends on yellow cellular MTT reduction by mitochondrial dehydrogenase enzyme from living cells form blue to purple formazane crystals. Formazan formed was analyzed by GloMax-Multi Microplate Multimode Reader (Promega) to measure the absorbance. The absorbance measurements obtained was compared with the control. The control in MTT Assay was Huh7 cell grown in cultured medium at well without the addition of nanofiber membrane sample. The magnitude of absorbance was comparable to percentage of viability living cells. The darker purple color of the formazan shows the increase of absorbance, indicating that cell viability was higher (Khoswanto et al., 2008). If percentage of measured cell viability was less than $60 \%$ then the resulting nanofiber has toxic properties and kills living cells.

The cytotoxicity test in this research was performed to PCL nanofiber, PCL-collagen with the addition of citric acid, and PCLcollagen treated with heating. PCLcollagennanofiber with the addition of citric acid and heat-treated was selected because theyhave good mechanical properties compared to other treated nanofiber. Both of these nanofiber have a larger young modulus values due to crosslinking effect given on nanofiber. Heating and addition of crosslinking agents such as citric acid was method to improve the mechanical properties of materials. While PCL nanofiber was chosen to compare the effect of collagen addition on nanofiber to cell viability. The nanofiber application in this study will be used as wound dressing which will be in direct contact with 


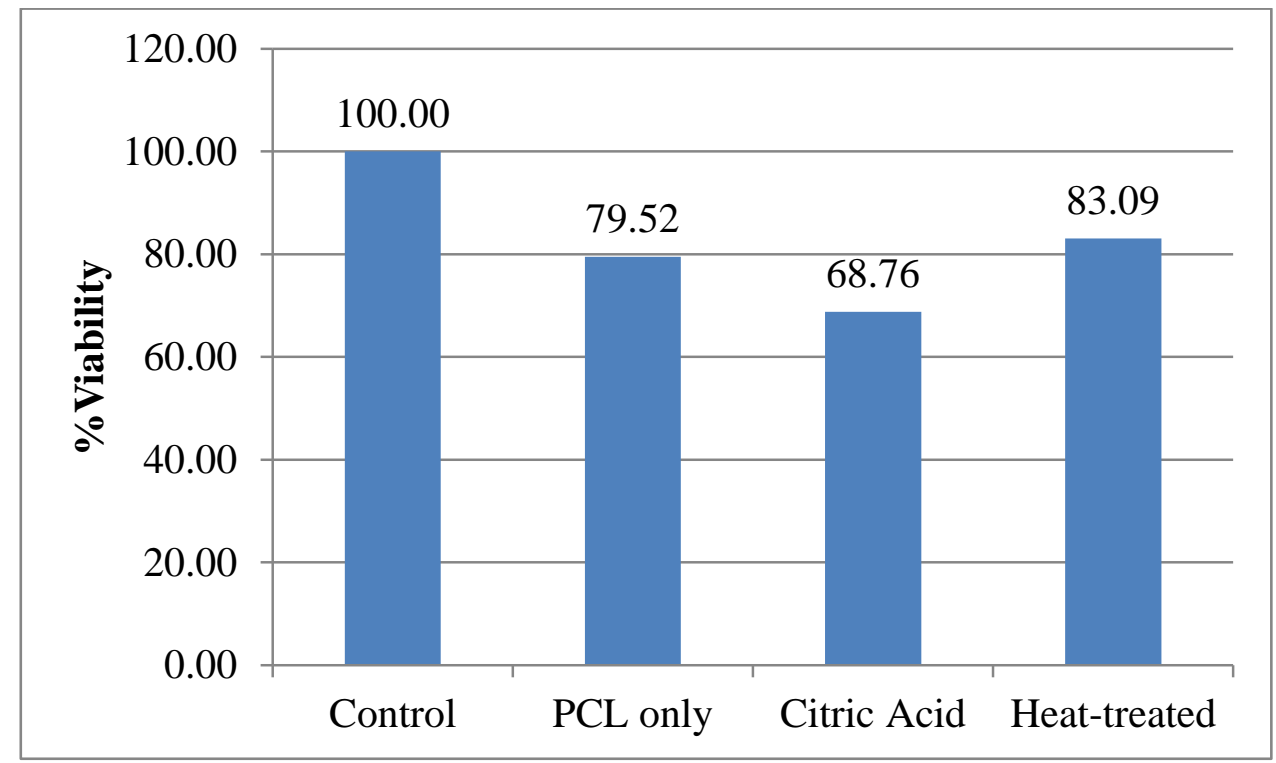

Figure 13. Percentage of cell viability

Based on the above graph data in Fig.13, heat-treatedPCL-collagen nanofiber has highest percentage of cell viability of $83.09 \%$, followed by PCL nanofiber with a cell viability percentage of $79.02 \%$, and PCLcollagen nanofiber with addition of citric acid as a crosslinker of $68.76 \%$. From these results, it can be seen that the addition of collagen in PCL-collagen nanofiber provides higher percentage of cell viability than without collagen. Collagen also has an important role for the growth and differentiation of cells in tissue culture (Rho et al., 2006).

PCL-collagen heat-treated nanofiber provides better percentage of cell viability than PCL-collagen nanofiber with the addition of citric acid. Although both treatments were crosslinking methods but provide different activities. The acidic properties of citric acid may caused cells can not survive with extreme $\mathrm{pH}$ environments which shows the smallest percentage of cell viability (Khoswanto et al., 2008). Chemical crosslinking such as the addition of citric acid affects cell adhesion thereby reducing the percentage of viability and cell proliferation (Franco et al., 2012). Thus, PCL-collagen nanofiber with heated treatments wasmore suitable for wound dressing as the result of MTT Assay in percentage of cell viability of $83.09 \%$. The increasing percentage of cell viability suggests that the nanofiber sample has non-toxic properties.

\section{CONCLUSIONS}

The preparation of polymer solution for nanofiber in this research was by dissolving PCL and collagen separately, polycaprolactone in chloroform while collagen in formic acid, then blending both each other. Fromfive treatments provided in fabrication of nanofiber, PCL-collagen nanofiber has 
diameter of about 200-600 nm. However, based on tests of mechanical properties, the addition of collagen in these nanofiber causes the membrane mechanical properties to be lower when compared to crosslinking treatments with heated or addition of citric acid. The cytotoxicity test in this study was performed on PCL, PCL-collagen with the addition of citric acid, and heated-treatments PCL-collagen nanofiber. PCL-collagen nanofiber with treatment of heating provides better viability percentage of $83.09 \%$ compared to nanofiber added citric acid as crosslinker so it is suitable to be applied as wound dressing, because the influence of citric acid has acidic properties causes the environment around the membrane has an extreme $\mathrm{pH}$ that may affect cell growth and reduced its viability.

\section{REFFERENCES}

1. Abrigo, M., McArthur, S.L., Kingshott, P., 2014, Electrospun Nanofibers as Dressings for Chronic Wound Care: Advances, Challenge, and Future Prospect, Macromolecular Bioscience, 14 (6), 772 792.

2. Amalia, N., 2012, Sintesis dan Karakterisasi Polimer Pati Sagu (Sago starch) dengan PEG 1000 menggunakan Asam Sitrat sebagai Crosslinking Agent, Skripsi, Fakultas Matematika dan Ilmu Pengetahuan Alam Universitas Jember.

3. Buttafoco. L., Kolkman, N.G., EngbersBuijtenhuijs, P., Poot, A.A., Dijkstra, P.J., Vermes, I., Feijen, J., 2006, Electrospinning of Collagen and Elastin for
Tissue Engineering Applications, Biomaterials, 27 (5), 724 - 734.

4. Callister Jr., W.D., \& Rethwisch, D.G., 2014, Material Science and Engineering: An Introduction $9^{\text {th }}$ Edition, John Wiley and Sons Inc, United State of America.

5. Dulnik, J., Denis, P., Sajkiewiwicz, P., Kolbuk, D., Choinska, E., 2016, Biodegradation of Biocomponent PCL/Gelatin and PCL/Collagen Nanofibers Electrospun from Alternative Solvent System, Polymer Degradation and Stability, 130, 10 - 21.

6. Franco, R.A., Min, Y.K., Yang, H.Y., Lee, B.T., 2012, On Stabilization of PVPA/PVA Electrospun Nanofiber Membrane and Its Effect on MaterialProperties and Biocompatibility, Journal of Nanomaterials, Hindawi Publishing Corporation.

7. Huang, Z.M., Zhang, Y.Z., Kotaki, M., Ramakrishna S.A., 2003, A Review on Polymer Nanofibers by Electrospinning and Their Applications in Nanocomposites, Composite Science and Technology, 63 (15), 2223 - 2253.

8. Khoswanto, C., Arijani, E., Soesilawati, P., 2008, Cytotoxicity Test of 40, 50 and $60 \%$ Citric Acid as Dentin Conditioner by using MTT Assay on Culture Cell Line, Dental Journal, 41 (3), 103 - 106.

9. Maneji, S.S., Scott, J., Page, J.Y.S., 2014, Process Optimization for the Electrospinning of Polycaprolactone Nanofibers Using Non-halogenated Solvents, International Conference on New Trends in Transport Phenomena, 82, $1-8$. 
10.Nomura, Y., Sakai, H., Ishii, Y., Shirai, K., 1996, Preparation and Some Properties of Type I Collagen from Fish Scales, Bioscience, Biotechnology, and Biochemistry, 60 (92), 2092 - 2094.

11.Pra, M.A.A.D., Valle, R.M.R.D., Maraschin, M., Veleirenho, B., 2017, Effect of Collector Design on The Morphological Properties of Polycaprolactone Electrospun Fibers, Materials Letters, (193), 154 - 157.

12.Rajput, M., 2012, Optimization of Electrospinning Parameters to Fabricate Aligned Nanofibers for Neural Tissue Engineering, Thesis, Department of Biotechnology and Medical Engineering National Institute of Technology Rourkela. 13.Rho, K.S., Jeong, L., Lee, G., Seo, B.M., Park, Y.J., Hong, S.D., Roh, S., Cho, J.J., Park, W.H., Min, B.M., 2006, Electrospinning of Collagen Nanofibers: Effects on The Behavior of Normal Human Keratinocytes and Early-stage Wound Healing, Biomaterials, 27 (8), 1452 - 1461. 14.Schueren, L.V.D., Schoenmaker, B.D., Kalaoglu, O.I., Clerck, K.D., 2011, An Alternative Solvent System for The Steady State Electrospinning of Polycaprolactone, European Polymer Journal, 47, 1256 1263.

15.Zeybek, B., Duman, M., Urkmez, A.S., 2014, Electrospinning of Nanofibrous Polycaprolactone (PCL) and Collagenblended Polycaprolactone for Wound Dressing and Tissue Engineering, Usak University Journal of Material Science, 1, $121-134$.
16.Zhang, Y.Z., Venugopal, J., Huang, Z.M., Lim, C.T., Ramakrishna, S., 2005, Characterization of The Surface Biocompatibility of The Electrospun PCLCollagen Nanofibers Using Fibroblasts, Biomacromolecules, 6 (5), 2583 - 2589. 